\title{
Gait Patterns for Crime Fighting: Statistical Evaluation
}

\author{
Kateřina Sulovská*, Silvie Bělašková, Milan Adámek \\ Tomas Bata University in Zlin, Faculty of Applied Informatics, nam. T. G. Masaryka 5555, 76001 \\ Zlin, the Czech Republic; * sulovska@ fai.utb.cz
}

\begin{abstract}
The criminality is omnipresent during the human history. Modern technology brings novel opportunities for identification of a perpetrator. One of these opportunities is an analysis of video recordings, which may be taken during the crime itself or before/after the crime. The video analysis can be classed as identification analyses, respectively identification of a person via externals. The bipedal locomotion focuses on human movement on the basis of their anatomical-physiological features. Nowadays, the human gait is tested by many laboratories to learn whether the identification via bipedal locomotion is possible or not. The aim of our study is to use 2D components out of 3D data from the VICON Mocap system for deep statistical analyses. This paper introduces recent results of a fundamental study focused on various gait patterns during different conditions. The study contains data from 12 participants. Curves obtained from these measurements were sorted, averaged and statistically tested to estimate the stability and distinctiveness of this biometrics. Results show satisfactory distinctness of some chosen points, while some do not embody significant difference. However, results presented in this paper are of initial phase of further deeper and more exacting analyses of gait patterns under different conditions.
\end{abstract}

Keywords: identification, bipedal locomotion (gait), biometrics, statistics, metronome, music, exercise, VICON

\section{INTRODUCTION}

Biometric systems are a fast growing segment of the market as everyone wants to protect their assets and lives primarily. The usual aim of the biometric system is not to allow an intruder into a protected area. Some features used as a biometric recognition can be also used as a part of a surveillance or monitoring systems - e.g. the face and gait recognition. The face recognition surveillance is nowadays used by many states to protect their assets like stadiums, casinos, banks, airports. Optimally, the violator is not allowed to access the area or they are monitored to be found if necessary to eliminate the potential risk. The gait recognition, which shows great potential to be used the same way as the face recognition is being tested as it may provide heightened security level as the gait stereotype cannot be covered as the face can. Uniting the gait and the face recognition system (a multi-biometric system) could increase the security level and the identification match score so that the identification of suspect of an offence or terrorists is inevitable.

The process of recognizing the human gait is made by our brains unconsciously every time we met a person. This ability is mainly known to those of us who has problems with eyes and suffers from an eye disease like myopia. Such people, when they are without their visual aids, recognize people according to the shape of their body, clothes colour or characteristic movements they do when walking. This ability is therefore one of the fundamental ideas of recognising the human gait by machine vision. The machine vision itself is very demanding process which consists of various algorithms and theories.

However, this article focuses only on the gait recognition's potential as a biometrics that can be utilized by surveillance/monitoring systems, respectively on behaviour of the characteristics during various conditions. As the task to analyse human movement in 3D is very demanding, we are presenting the initial part of our research dealing with the 2D information in the $z$ axis, which represents data as can be taken by the common cameras in the streets (in our case in ideal setting). The majority of research articles connected with the gait analyses are mainly from the field of medicine, rehabilitation and surgery (e.g. impact of diseases, prosthodontics, rehabilitation, analyses of fall risks), industry (e.g. computer games design, animations), horsemanship and veterinary, robotics and sport industry. The scientific field

Optic and Photonics for Counterterrorism, Crime Fighting and Defence IX; and Optical Materials and Biomaterials in Security and Defence Systems Technology X, edited by Douglas Burgess, Gari Owen, Roberto Zamboni, Francois Kajzar, Attila A. Szep, Proc. of SPIE Vol. 8901, 89010G · C 2013 SPIE · CCC code: 0277-786X/13/\$18 · doi: 10.1117/12.2033323 
includes issues like difference between genders, age, race, acoustics of gait on different surfaces, effects of speed and treadmills, influence of menstruation cycle on women, sports behaviours, routine activities and their influence on body, effect of shoe fit or generally shoes on gait patterns, etc. The conditions chosen for our experiments have not been used or published so far.

\section{METHODOLOGY}

\subsection{Subjects}

Total 21 healthy students of the field Security Technologies, Systems and Management from Tomas Bata University in Zlín participated on the measurements. Unfortunately, only data from 12 volunteers ( 6 women and 6 men) was utilizable for our research due to the fact that some of the partakers did not have marker's trajectories for some tested parts of our research and were therefore excluded. These participants, aged 19 to 30 years, did not claim to have any serious pathology, injury or any posttraumatic history in their musculoskeletal system prior to the measurement. Neither of them, except one woman, practices sports regularly since childhood. The only woman doing sport is an athlete (hammer $\&$ discus thrower).

Table 1. Basic characteristics and biometric data of subjects

\begin{tabular}{c|cccc|} 
Descriptive statistics & Age [year] & Weight $[\mathrm{kg}]$ & Height $[\mathrm{cm}]$ & BMI \\
\hline Mean $( \pm S D)$ & $23.45( \pm 3.54)$ & $77.61( \pm 18.31)$ & $178.17( \pm 8.73)$ & $24.41( \pm 5.13)$ \\
Maximum $($ Max $)$ & 30.05 & 119.10 & 193.50 & 35.18 \\
Minimum $($ Min $)$ & 19.43 & 47.70 & 161.00 & 16.31 \\
Mean women $( \pm S D)$ & $24.50( \pm 3.54)$ & $66.52( \pm 9.47)$ & $167.33( \pm 3.85)$ & $23.87( \pm 3.94)$ \\
Mean men $( \pm S D)$ & $23.04( \pm 1.76)$ & $82.05( \pm 19.10)$ & $182.50( \pm 5.92)$ & $24.62( \pm 5.52)$ \\
\cline { 2 - 5 } & & &
\end{tabular}

\subsection{Measurement set up}

The Vicon MX T020 system from Vicon Motion System Ltd., UK was used as the motion capture system for 3D data acquisition at the University Hospital Brno's specialized Gait Lab. The system was designed for clinical applications in orthopaedics and rehabilitation especially of kids. The movement is captured by eight cameras with infrared filters detecting passive retro-reflexive markers placed on human body moving in the calibrated space (s. Figure 1). For the self analysis, a double-step was chosen. The height of cameras was between $1.4-2.5 \mathrm{~m}$ with the frequency of $120 \mathrm{frames} / \mathrm{s}$. The model used included 37 markers $(19 \mathrm{~mm}$ in diameter $)$ placed on anatomically significant places (PlugInGaitFullBody model, based on Newington-Helen Hayes model) as can be seen in Figure 1. Those parts, respectively their widths/lengths together with the basic anthropometric data were defined before the beginning of experiments. For further analyses, data were exported to *.CSV.

In our study, we conducted the assumptions that the gait is a typical characteristic for each individual. Based on [1], the best visible anatomical landmarks from the marker model were selected to obtain marker's trajectory in $2 \mathrm{D}$ (sagittal plane) in millimetres as this part of the research is focused on recognition of a person in ideal camera surveillance system (a marker free analysis $[2,3])$, where we are unable to get 3D data. Following markers were selected for testing: $\mathrm{C} 7\left(7^{\text {th }}\right.$ Cervical vertebrae), L(R)FHD (front head), L(R)BHD (back head), L(R)TOE (toe - second metatarsal head on the midfoot side of the equinus break between fore- and mid-foot), R(L)SHO (shoulder - acromioclavicular joint), R(L)ELB (elbow - lateral epicondyle approximating elbow joint axis), R(L)ASI (anterior superior iliac spine points), R(L)HIP (hip - superior aspect of greater trochanter), R(L)WRB (wrist bar little finger side), R(L)THI (thigh - lower later $1 / 3^{\text {rd }}$ surface of the thigh), R(L)KNE (knee - lateral epicondyle), R(L)TIB (tibial wand - over the lower $1 / 3^{\text {rd }}$ of the shank), R(L)ANK (ankle - lateral malleolus along an imaginary line that passes through the transmalleolar axis); where $\mathrm{R}$ is for the right side, $\mathrm{L}$ is for the left side. 



Figure 1. Measurement in the Gait lab (left - participant, right - MoCap software screenshot)

All the measurements were conducted within the same conditions (ambient temperature $22{ }^{\circ} \mathrm{C}$, no air-conditioning, markers attached directly on body - swimsuit-dressed participants). The measurements were focused on one stride cycle length analysis (also called one double-step). The task for our participants was to pass through the selected corridor 10 times, with the emphasis on hitting the force plates as much as possible.

\subsection{Walking conditions}

The measurements were done for 8 different situations in laboratory with ambient temperature $22{ }^{\circ} \mathrm{C}$. As the influence of different clothing, footwear, health conditions or replacement use was published by other authors [4-13], our research focus on various conditions before and during walking through marked corridor (shoeless, swimsuit-dressed participants):

- $\quad$ normal gait - self-selected natural speed (used as a template for further collation),

- $\quad$ after workout walking - self-selected natural speed after longer deep squatting position (4 min. for women, $6 \mathrm{~min}$. for men), walking immediately after workout,

- walking into the rhythm - walking into beats of metronome at 4 different paces:

○ MM. 60, MM. 92, MM. 120, MM. 144,

- $\quad$ walking with music - walking with the music background:

○ slow music, moderate dynamic music.
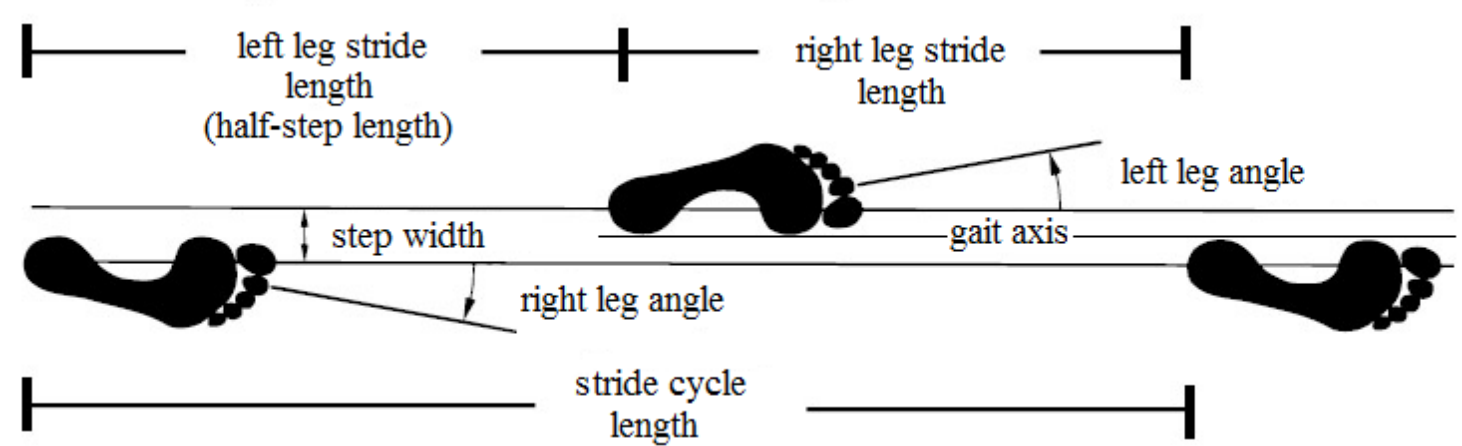

Figure 2. Length parameters of gait - assumed from [1] 


\subsection{Data analysis}

After each person pass through the selected corridor, their recordings were rendered and the software smoothed and filtered obtained data. The initial contact and swing phase of stride cycle were detected where it was possible according to the force plates. As the Tomas Bata University in Zlin does not have the VICON MoCap system or VICON software, all measured data were converted into *.CSV format to be used for calculations in the MS Excel 2010 and the STATISTICA software.

For the human gait patterns analysis, tools for qualitative and quantitative analysis were chosen. Kinematics of gait was mainly focused on the position change, while velocities and accelerations were not analysed in this initial phase of research. However, as the data processing is time-consuming process, only statistical analysis of curves' averages was done for the purpose of this article. Also, a hypothesis was set:

\section{$H_{0}$ : the mean-value is similar for all groups ; $H_{l}$ : the mean-value differs at least in one pair}

For statistical analyses following tests were used: descriptive statistics, paired t-test, one dimensional test of significance, Two-way ANOVA, and Tuckey HSD test. All tests were performed in the STATISTICA v. 7, software by StatSoft Inc.

\section{RESULTS}
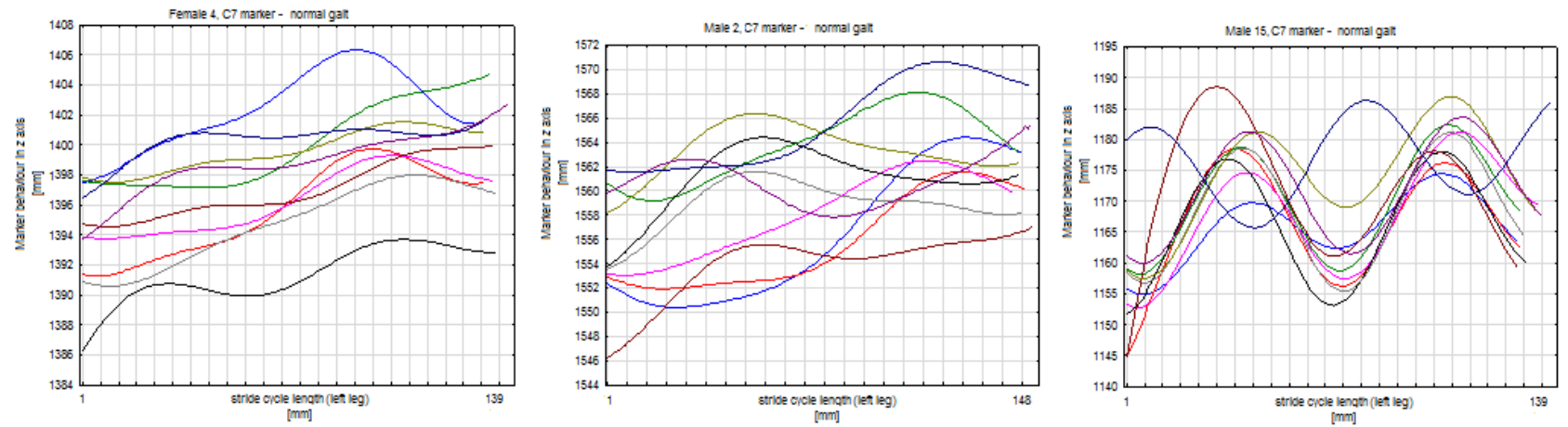

Figure 3. Examples of different behaviour of $\mathrm{C} 7$ marker curves during normal gait of 3 different participants (from left to right: Female 4, Male 2, and Male 15)

For each subject involved in experiments 8 simple tables with the results of 10 measurements of set conditions were done to be further compared. Variables walking speed, walking rate, and coefficient of variance $(C V)$ were counted. For each measurement the $p$-value was counted by the t-test with the $95 \%$ confidence interval. The p-value was very low for the intra-individual comparison, which means that within 10 measurements the values were statistically significantly different and therefore showed variability within measurement for each measured parameter and for each measured person.

Table 2. Example of time and space parameters of gait (Female 1) - intra-individual comparison, normal gait

\begin{tabular}{|c|c|c|c|c|c|c|c|c|c|c|c|c|c|c|}
\hline Subject & Side & 1 & 2 & 3 & 4 & 5 & 6 & 7 & 8 & 9 & 10 & Mean & SD & CV \\
\hline \multirow{2}{*}{ Stride cycle length $[\mathrm{m}]$} & left & 1.38 & 1.25 & 1.13 & 1.14 & 1.25 & 1.27 & 1.18 & 1.29 & 1.37 & 1.4 & 1.27 & 0.09 & 7.3 \\
\hline & right & 1.19 & 1.15 & 1.2 & 1.23 & 1.25 & 1.19 & 1.2 & 1.17 & 1.24 & 1.15 & 1.2 & 0.03 & 2.68 \\
\hline \multirow{2}{*}{ Stride cycle time $[\mathrm{s}]$} & left & 1.15 & 1.5 & 0.94 & 0.95 & 1.5 & 1.6 & 0.98 & 1.7 & 1.14 & 1.17 & 1.5 & 0.08 & 7.3 \\
\hline & right & 0.99 & 0.96 & 1 & 1.3 & 1.4 & 1 & 1 & 0.98 & 1.4 & 0.96 & 1 & 0.03 & 2.68 \\
\hline \multirow{2}{*}{ Walking speed $[\mathrm{m} / \mathrm{s}]$} & left & 1.31 & 1.2 & 1.8 & 1.9 & 1.2 & 1.21 & 1.12 & 1.23 & 1.3 & 1.34 & 1.21 & 0.09 & 7.3 \\
\hline & right & 1.19 & 1.16 & 1.2 & 1.23 & 1.25 & 1.2 & 1.2 & 1.18 & 1.24 & 1.16 & 1.2 & 0.03 & 2.68 \\
\hline \multirow{2}{*}{ Walking rate [no. of steps/min] } & left & 52.33 & 57.42 & 63.83 & 63.16 & 57.42 & 56.69 & 61.22 & 55.99 & 52.63 & 51.28 & 57.2 & 4.21 & 7.36 \\
\hline & right & 60.5 & 62.39 & 60 & 58.44 & 57.6 & 60.3 & 60 & 61.33 & 57.97 & 62.39 & 60.09 & 1.61 & 2.67 \\
\hline \multirow{2}{*}{ Half-step length [m] } & left & 0.64 & 0.62 & 0.66 & 0.69 & 0.67 & 0.63 & 0.62 & 0.63 & 0.63 & 0.64 & 0.64 & 0.05 & 8.2 \\
\hline & right & 0.75 & 0.62 & 0.61 & 0.63 & 0.65 & 0.68 & 0.64 & 0.61 & 0.65 & 0.54 & 0.64 & 0.05 & 8.2 \\
\hline \multirow{2}{*}{ Step width $[\mathrm{m}]$} & left & 0.34 & 0.53 & 0.34 & 0.59 & 0.52 & 0.5 & 1.7 & 0.87 & 0.79 & 0.69 & 0.63 & 0.22 & 35.37 \\
\hline & right & 0.59 & 0.39 & 0.31 & 0.23 & 0.44 & 0.4 & 0.42 & 0.68 & 0.42 & 1.11 & 0.5 & 0.24 & 47.04 \\
\hline
\end{tabular}


The basic descriptive statistics, as can be seen in Table 2., was also used for inter-individual testing. This analysis showed that the most differential parameters are step width, step length and walking speed. However, as this comparison is very simple and the CVs are about $9.65 \%$, the particular difference of individuals during their reciprocal comparison was not imaged.

The second part of our research focuses on analyses of 25 markers. The results from two-way ANOVA with interactions where significance level alpha $=0.05$ showed significant interaction and partial effects in $92 \%$ of chosen markers except LHEE and LELB markers. The Tuckey HSD test, which presented the method of pairwise comparison for crossing, for both men and women group displayed $88 \%$ of markers with similarity to at least two other measurement conditions and 12 markers turned out similar between men and women in different measurement conditions. The same test utilized only for the type of gait regardless gender evaluated as statistical significant difference in normal gait and: Slow music - $20 \%$ of total cases, MM. 144 - 20\% of cases total, MM.60 - 32\% of cases total, After workout - 32\% of total cases, MM.92 $40 \%$ of cases total, MM. $120-44 \%$ of total cases, Fast music $-48 \%$ of total cases.

Table 3. Paired t-test result examples of differences between mean-values of curves for RANK and LANK

\begin{tabular}{|c|c|c|c|c|c|c|c|c|c|c|c|c|}
\hline & & $\mathrm{F} 1$ & $\mathrm{~F} 2$ & F3 & F4 & F5 & F6 & M2 & M4 & M9 & M10 & M12 \\
\hline Diff & & -0.44 & 1.08 & 4.70 & -0.82 & 2.28 & 4.98 & -12.67 & -5.04 & -5.04 & -3.04 & -12.19 \\
\hline $\mathrm{t}$ & 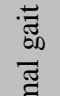 & -0.11 & 2.22 & 3.50 & -0.40 & 2.30 & 3.95 & -18.50 & -2.81 & -2.81 & -3.13 & -4.26 \\
\hline $\mathrm{DF}$ & $\bar{z}$ & 122 & 141 & 132 & 134 & 118 & 114 & 147 & 130 & 131 & 140 & 131 \\
\hline $\mathrm{p}$ & & 0.91 & 0.03 & 0.00 & 0.67 & 0.02 & 0.00 & 0.00 & 0.01 & 0.01 & 0.00 & 0.00 \\
\hline Diff & & -4.02 & 1.03 & 1.03 & -6.93 & 2.62 & -8.63 & -19.12 & -37.25 & -2.89 & -1.28 & -12.54 \\
\hline $\mathrm{t}$ & $\begin{array}{l}8 \\
8 \\
\end{array}$ & -2.18 & 0.45 & 0.86 & -2.46 & 0.91 & -3.31 & -75.34 & -15.18 & -8.30 & -1.50 & -30.80 \\
\hline DF & 之 & 214 & 120 & 125 & 116 & 117 & 118 & 245 & 124 & 125 & 128 & 122 \\
\hline $\mathrm{p}$ & & 0.03 & 0.65 & 0.39 & 0.02 & 0.37 & 0.00 & 0.00 & 0.00 & 0.00 & 0.14 & 0.00 \\
\hline Diff & & -1.12 & 1.66 & 1.50 & -1.15 & 3.92 & -1.05 & -14.41 & -10.33 & -4.04 & -2.40 & -8.41 \\
\hline $\mathrm{t}$ & $\begin{array}{l}\overrightarrow{0} \\
\frac{a}{0} \\
\vdots\end{array}$ & -0.26 & 2.03 & 2.91 & -0.55 & 32.10 & -1.64 & -14.14 & -3.23 & -5.86 & -1.05 & -4.03 \\
\hline $\mathrm{DF}$ & $\sum_{\frac{E}{z}}^{\dot{E}}$ & 117 & 135 & 129 & 121 & 115 & 119 & 133 & 132 & 127 & 136 & 123 \\
\hline $\mathrm{p}$ & & 0.79 & 0.44 & 0.00 & 0.58 & 0.00 & 0.10 & 0.00 & 0.00 & 0.00 & 0.29 & 0.00 \\
\hline
\end{tabular}

The t-test was also used to test the left and right marker of the body segment of each person and experimental condition. The distinction between average mean-values shows sufficient dissimilarity between right and left marker, which means inapplicability of only one side of the body for the recognition purposes and therefore substitution between right and left side cannot be recommended for a proper human identification during a movement. Nevertheless, disproportions of 
human gait can be used not only for the recognition of specifics in the individual's bipedal locomotion but also for detection of disorders in musculoskeletal system of the human body (medical analysis).

\section{CONCLUSION}

The gait recognition is still one of the most recent technologies in the field of biometrics. Even though the study of movement is not a young field, recognizing human being by its gait patterns is given its chance. Many laboratories and scientific teams are trying to create best software application to be able to recognize human movement patterns for more than 30 years by now. In the recent history, the gait patterns were evaluated manually which took plenty of careful work hours. Nowadays, the rapid development of technique enables to save time by using sophisticated software and to investigate human gait patterns by using the $3 \mathrm{D}$ technique.

The future may contain the biometric recognition based on the gait analysis, where ill, injured or endangered persons will be detected automatically by a remote surveillance; and violators, ambushers, terrorists and other suspects will be detected before they will have an opportunity to harm or damage protected interests. Such future could have, on the other hand, some disadvantages - mistaken identity, falsely accused people, lack of freedom in some way, protests against such surveillance, and many more. It will be necessary to consider all the pros and cons, public opinions and overall morale of the population in the country. We must always bear in mind that no system is perfect and everything is exploitable, even though it was originally intended for a good thing.

Our paper presents novel results in the field of gait recognition analysis. The experimental data show usability for gait patterns recognition biometrics in a smaller volume e.g. in small companies. The initial results of our experiments showed sufficient similarity between markers and subjects. This means most of the conditions we used should not influence the subject's biometric comparison to the template and also means the gait behaviour in some areas is not changed expressively by conditions. However, the tests pointed out to some issues with marker interchangeability and conditions' influence to some markers. Our future work will be focused on deeper statistical analyses of each experimental condition to get more accurate and predicative results.

After obtaining data set of the gait patterns big enough (hundreds of people) it could be said whether the successful gait recognition for security purposes is possible or not. So far the variability of the gait appears to be big enough, but further testing with a greater amount of people under more different conditions is necessary to be able to say this with certainty.

\section{ACKNOWLEDGEMENTS}

This paper is supported by the Internal Grant Agency at Tomas Bata University in Zlín, project No. IGA/FAI/2013/001, and by the European Regional Development Fund, project No. CZ.1.05/2.1.00/03.0089 (CEBIATech). We would like to thank the Gait lab at the University Hospital Brno, especially Mr. Jan Jadrný and prof. Jan Poul, for the help with measurement on VICON system.

\section{REFERENCES}

[1] Dolná, Z., [Analýza variability parametrov chôdze a možnosti jej využitia v biometrike], Dissertation Thesis, Technical University Košice (2010), in Slovak language.

[2] Šimšík, D., Porada, V., et al, [Analýza pohybu človeka pri identifikácii osôb v kriminalistike], Edícia vedeckej a odbornej literatúry, Strojnická fakulta TU v Košiciach, Košice, ISBN 978-80-553-0023-8, (2008), in Slovak language.

[3] Majerník, J., and Šimšík, D., "Marker-free Analysis of Human Gait”, Lékař a technika, Vol. 37, No 1, 23 - 27 (2007).

[4] Ikizler, N, [Understanding Human Motion: Recognition and Retrieval of Human Activities], Dissertation Thesis, Bilkent University (2008).

[5] Wasik, J., "Kinematic analysis of the side kick in Taekwon-do", Acta of Bioengineering and Biomechanics, Vol. 13, No. 4 (2011). 
[6] Silveira J Jr., J. C. S., Musse, R. S., Jung, C. R., “Crowd Analysis Using Computer Vision Techniques”, IEEE Signal Processing Magazine, ISSN 1053-5888 (2010).

[7] Švehlík, M., Zwick, E. B., Steinwender, G., Kraus, T., and Linhart, W. E., "Instrumental gait analysis in patients with cerebral palsy", Neurol. praxi, 12(4): 230 - 233 (2011).

[8] Abadi, F. H., Muhamad, T. A., and Salamuddin, N., "Energy Expenditure through Walking: Meta Analysis on Gender and Age", Procedia Social and Behavioral Sciences 7(C) 512 - 521 (2010).

[9] Alpert, D. T., and Allen, M., “Acoustic Gait Recognition on a Staircase”, World Automation Congress (2010)

[10] Boyer, K. A., Beaupre, G. S., and Andriacchi, P., "Gender differences exist in the hip joint moments of healthy older walkers", Journal of Biomechanics 41, 3360 - 3365 (2008).

[11] Doi, T., Yamaguchi, R., Asai, T., Komatsu, M., Makiura, D., Shimamura, M., Hirata, S., Ando, H., and Kurosaka, M., "The effects of shoe fit on gait in community-dwelling older adults", Gait \& Posture 32, $274-$ 278 (2010).

[12] Helbostad, J. L., Vereijken, B., Hesseberg, K., and Sletvold, O., "Altered vision destabilizes gait in older persons", Gait \& Posture 30, 233 - 238 (2009).

[13] Clark, R. A., Bartold, S., and Bryant, A. L. , "Tibial acceleration variability during consecutive gait cycles is influenced by the menstrual cycle", Clinical Biomechanics, Volume 25, Issue 6, Pages 557 - 562 (2010). 